\title{
A regenerative label-free fiber optic sensor using surface plasmon resonance for clinical diagnosis of fibrinogen
}

This article was published in the following Dove Press journal:

International Journal of Nanomedicine

27 August 2015

Number of times this article has been viewed

\section{Tan Tai Nguyen' \\ Sun Oh Bea' \\ Dong Min Kim² \\ Won Jung Yoon ${ }^{3}$ \\ Jin-Won Park ${ }^{4}$ \\ Seong Soo A An' \\ Heongkyu Ju ${ }^{1,5,6}$}

'Department of Bionano Technology, College of Bionano Technology,

Gachon University, Seongnam,

${ }^{2}$ Department of Materials Science and

Engineering, Hongik University, Sejong

City, ${ }^{3}$ Department of Chemical and

Bio Engineering, Gachon University,

Seongnam, ${ }^{4}$ Department of Chemical

and Biomolecular Engineering, College

of Energy and Biotechnology, Seoul

National University of Science and

Technology, Seoul, ${ }^{5}$ Department of

Nanophysics, College of Bionano

Technology, Gachon University,

Seongnam, ${ }^{6}$ Neuroscience Institute,

Gil Hospital, Incheon, South Korea

Correspondence: Heongkyu Ju

Department of Nanophysics, College of

Bionano Technology, Gachon University,

Seongnam 46I-70I, Gyeonggi-do,

South Korea

Tel/fax +82 27508552

Email batu@gachon.ac.kr

Seong Soo A An

Department of Bionano Technology,

College of Bionano Technology,

Gachon University, Seongnam 46I-70I,

South Korea

Email seongaan@gachon.ac.kr
Purpose: We present the regenerative label-free fiber optical biosensor that exploits surface plasmon resonance for quantitative detection of fibrinogen (Fbg) extracted from human blood plasma.

Materials and methods: The sensor head was made up of a multimode optical fiber with its polymer cladding replaced by metal composite of nanometer thickness made of silver, aluminum, and nickel. The Ni layer coated allowed a direct immobilization of histidine-tagged peptide (HP) on its metal surface without an additional cross-linker in between. On the coated HP layer, immunoglobulin $\mathrm{G}$ was then immobilized for specific capturing of Fbg.

Results: We demonstrated a real-time quantitative detection of Fbg concentrations with limit of detection of $\sim 10 \mathrm{ng} / \mathrm{mL}$. The fact that the HP layer could be removed by imidazole with acid also permitted us to demonstrate the regeneration of the outermost metal surface of the sensor head for the sensor reusability.

Conclusion: The sensor detection limit was estimated to be $\sim 10 \mathrm{pM}$, which was believed to be sensitive enough for detecting Fbg during the clinical diagnosis of cardiovascular diseases, myocardial infarction, strokes, and Alzheimer's diseases.

Keywords: SPR, real-time assay, histidine-tagged peptide, protein sensing

\section{Introduction}

In the past few decades, optical biosensors have been developed for applications in food industry, biomedical assay, and monitoring of environmental elements and changes. ${ }^{1-3}$ A great deal of effort has been made on developing various techniques for biomedical assays that use detection labels such as fluorophores to attach target molecules for specific ${ }^{4}$ and quantitative detection. ${ }^{5,6}$ However, it was known that a label-assisted assay revealed several drawbacks, such as an operation time that did not permit real-time assay, relatively high costs, and lack of reproducibility due to an inevitable assay dependence on operators. ${ }^{78}$ Alternatively, a label-free assay, which could replace a need of using such labels by utilizing the conversion of interaction of the target molecules with their sensor surface into a transducer signal, has been highlighted, and a variety of its detection platforms have been reported for the clinical diagnosis. ${ }^{9-12}$ Label-free biosensors that may support real-time assay could secure the specific detection of target molecules usually by resorting to their bio-affinity reactions or immunoreactions. ${ }^{2,13,14}$

One of the most widely used label-free bio-assays was optical biosensing with surface plasmon resonance ${ }^{15-17}$ (SPR), due to sufficiently high sensitivity and signal-to-noise ratio, and immunity to external electromagnetic disturbance. SPR submit your manuscript | www.dovepress.com

Dovepress

http://dx.doi.org// 0.2147/IJN.S88963
International Journal of Nanomedicine 2015:10 (Special Issue on diverse applicatons in Nano-Theranostics) I55-163 I55 (c) (i) (5) 2015 Nguyen et al. This work is published by Dove Medical Press Limited, and licensed under Creative Commons Attribution - Non Commercial (unported, v3.0) License. The full terms of the License are available at http://creativecommons.org/licenses/by-nc/3.0/. Non-commercial uses of the work are permitted without any further permission how to request permission may be found at: http://www.dovepress.com/permissions.php 
is a resonant optical phenomenon occurring at an interface between a metal and a dielectric (eg, an aqueous medium), as a result of optical phase matching between evanescent waves of high propagation constant provided by attenuated total reflection (ATR), and nonradiative surface plasmon surface waves at the interface. This phase-matching condition, which governed the resonant coupling between those waves, can be altered sensitively with the refractive index of a dielectric in creating SPR occurrences at the interface with a metal. This resonant coupling condition could be served as a sensing principle for highly sensitive detection of concentration of target molecules in a quantitative and real-time manner. Recently, fiber optical SPR sensors have been demonstrated and brought considerable interest, owing to their miniaturized and simple structures, and their potential usability, as remote sensors with high sensitivity and wide dynamic range. ${ }^{18-22}$ However, a place where such remote sensors can be installed may not permit frequent replacement of sensor heads due to the limited accessibility, such as cosmic space, underground, and deserted lands with required sensor reusability.

Recently, histidine-tagged peptide (HP) on transition metals, such as $\mathrm{Cu}$ and $\mathrm{Ni}$, was used to demonstrate the immobilization of peptides or proteins without a covalent cross-linker, and HP could be dissociated from the metal by imidazole $^{23}$ (IM). This property led us to attempt to regenerate an SPR sensor surface, consisting of multilayers of a peptide, an antibody, and target proteins.

Extensive researches have shown that human plasma fibrinogen ( $\mathrm{Fbg}$ ) could be considered one of the possible biomarkers for estimating risks of atherosclerosis, ${ }^{24,25}$ cardiovascular diseases, ${ }^{26,27}$ and Alzheimer's disease. ${ }^{28}$ It was also known that the elevated levels of plasma Fbg enabled the prediction of myocardial infarction and strokes. ${ }^{29,30}$ There were several methods to measure Fbg concentration, such as Clauss method, which relied on measuring thrombin clotting time for Fbg concentration. ${ }^{31}$ However, it was known that this method did not allow the quantification of Fbg concentrations in a real-time manner.

In this paper, we demonstrate a regenerative fiber optical SPR biosensor for immunoassay with its metal composite (Ag-Al-Ni) sensor surface for the quantitative real-time detection of Fbg concentrations. The heterogeneous metal layers were coated for high sensitivity, wide dynamic range of detection, and regeneration of the sensor surface. We immobilized a HP layer on the Ni surface for subsequent adsorption of Fbg antibody (immunoglobulin G [IgG]), which could capture Fbg molecules specifically. We monitored the successive adsorption of each layer of a HP, an $\mathrm{IgG}$, and a human plasma-extracted Fbg in a real-time and quantitative manner. We also demonstrated that the sensor surface could eventually be regenerated $(>95 \%)$ by removing the immobilized HP layer with IM and additional acetic acid (ACT). The regeneration of Ni surface demonstrated the enhanced capability of multiple measurements of target molecules on the same sensor head. This removes the need for replacement of a sensor head for another assay of different targets, and thus eliminates possibility of substantial change in light-coupling efficiency into the sensor head. The current regenerative SPR biosensor could find potential applications for use in places with limited accessibility for replacing sensor head.

\section{Materials and methods Agents}

A HP $\left(\mathrm{H}_{2} \mathrm{~N}-\mathrm{HHHHHHGGHWRGWVS-COOH}\right)$ was synthesized by AnyGen Inc. (Kwangju, South Korea), while an IgG was purchased from EMD Millipore (Billerica, MA, USA). Histidine IM in HP could enable the coordinate metal bonding. Purified human Fbg was purchased from Sigma-Aldrich Co. (St Louis, MO, USA). Blocking buffer solution (B) was prepared for minimizing the nonspecific binding of injected Fbg to the HP layer, according to the block ace (AbDSerptec) instruction. All agents used were diluted with phosphate-buffered saline with Tween 20 (PBST; pH 7.4) obtained from Sigma-Aldrich Co.

\section{The SPR sensor head and sensing experimental setup}

A multimode optical fiber (JTFLH-Polymicro Technologies) with core diameter of $\sim 200 \mu \mathrm{m}$ was used to fabricate an SPR sensor head. A soldering machine was used to remove the polymer cladding of $5 \mathrm{~cm}$ length, and the subsequently exposed core surface was cleaned with solutions of ethanol and acetone for assuring the removal of remaining cladding substance. Using a thermal evaporator, the metal layers of $\sim 36 \mathrm{~nm}$ thickness with Ag and $\sim 4 \mathrm{~nm}$ thickness with Al were sequentially coated on the exposed fiber core for SPR excitation. ${ }^{22}$ Then, the radio-frequency magnetron sputter was used to deposit an Ni layer of $1 \mathrm{~nm}$ thickness, which should not significantly affect the SPR condition, determined by the coated Ag and Al.

A flow cell was made of polydimethylsiloxane in a circular shape with two ports for the inlet and outlet of flowing solutions. The heterogeneous metal-coated fiber was then installed into the flow cell. 


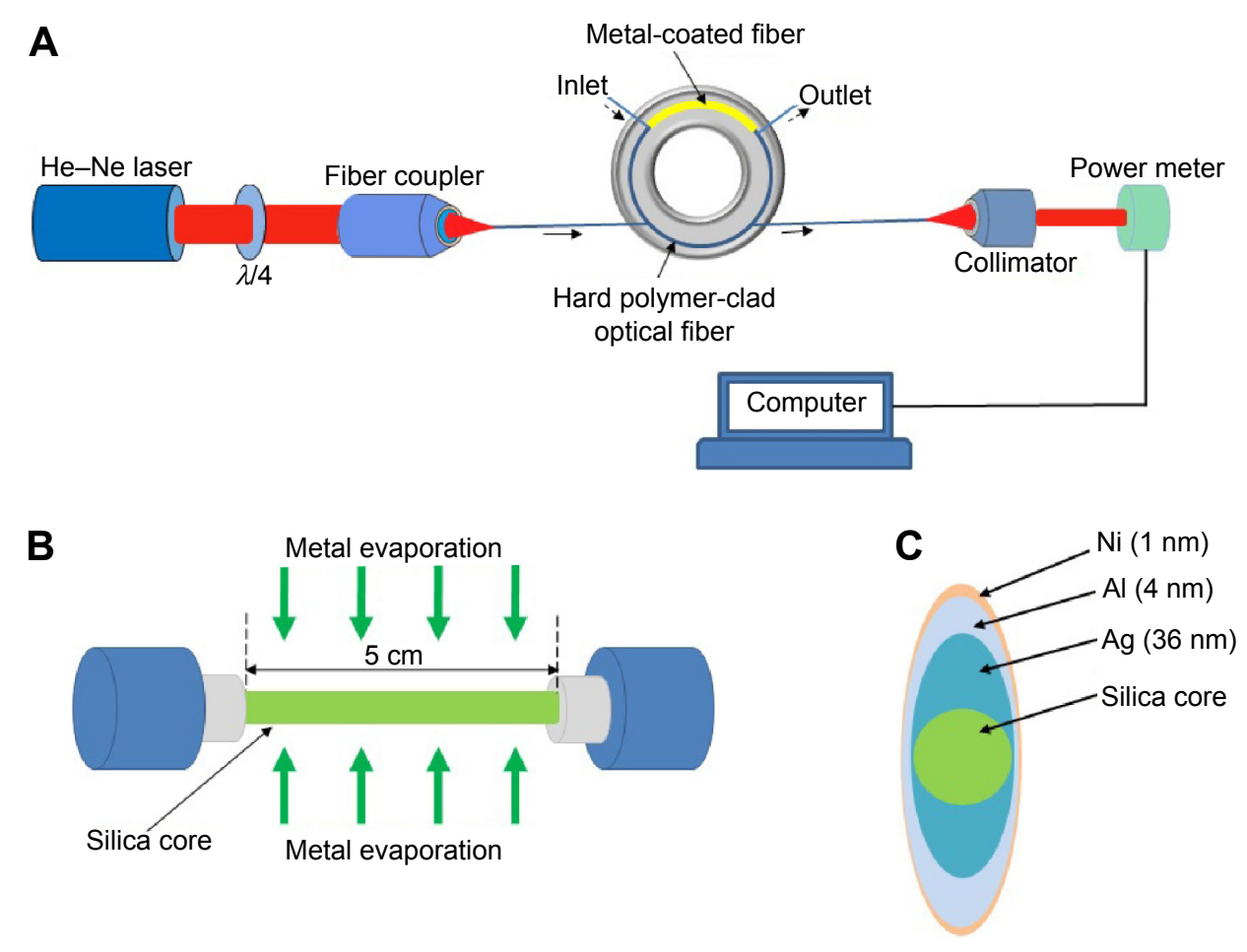

Figure I An experimental setup with a metal coated sensing head.

Notes: (A) Schematic of an experimental setup for label-free optical biosensing. (B) Metal coating on two opposite sides of the silica core. (C) Expected cross-section of metal-coated core of the fiber sensor.

Abbreviation: $\lambda / 4$, quarter-wave plate.

Figure 1A shows the schematic of the experimental setup for label-free optical biosensing, based on output power measurement. He-Ne laser was used as light source at a wavelength of $632.8 \mathrm{~nm}$. Laser light was coupled into the multimode optical fiber by an aspheric lens of a numerical aperture of 0.47 with its focus length of $4 \mathrm{~mm}$. The acceptance angle of the fiber was $\sim 21.72^{\circ}$. Light propagation through the clad-free fiber core of $5 \mathrm{~cm}$ length interfaced with coated layers of metals and supported multiple ATRs, and the injected solutions that flowed from an inlet to an outlet were expected to cause changes in output optical power, due to the SPR condition change. The fiber output light was collimated by an aspheric lens of a numerical aperture of 0.53 . Use of a power meter connected to a computer enabled us to measure fiber output power and recorded corresponding power meter signals at a sampling rate of $20 \mathrm{~Hz}$ for a real-time monitoring.

Figure 1B and Figure 1C show that the metal coating was made in an asymmetrical manner by evaporating the metals on two opposite sides of an exposed fiber core. ${ }^{22}$ Thus, at least half the light that coupled into the fiber could be used for SPR excitation by using a circular polarization of input light theoretically, which could be prepared by placing a quarter-wave plate $(\lambda / 4)$ before the fiber. Decreased output power was observed as solution was injected into the flowing channel, due to enhanced ATR, which was governed by an SPR phase-matching condition, given by:

$$
n_{\text {core }} \sin \theta_{\text {in }}=\operatorname{Re}\left[\sqrt{\frac{\mathcal{E}_{\mathrm{m}} \mathcal{E}_{\mathrm{s}}}{\mathcal{E}_{\mathrm{m}}+\varepsilon_{\mathrm{s}}}}\right]
$$

where $n_{\text {core }}$ was the fiber core refractive index, and $\theta_{\text {in }}$ was the incidence angle of light at a boundary between fiber core and coated metal. $\varepsilon_{\mathrm{m}}$ and $\varepsilon_{\mathrm{s}}$ were relative permittivities of the metal composite and a dielectric (an aqueous medium to be sensed) on the outermost metal $(\mathrm{Ni})$, respectively. The range of incidence angle at the core/cladding interface for total internal reflection was approximately $76^{\circ}-90^{\circ}$. The immobilization of injected substance caused increases in $\varepsilon_{\mathrm{s}}$ of the dielectric, leading to increased attenuation of reflected light off the fiber core. This resulted in a decrease in the fiber output power. It was known that the surface wave amplitude from the metal/dielectric interface decreased exponentially normal to the interface with a characteristic decay length $z$, as given by the following equation. ${ }^{32}$

$$
z=\frac{\lambda}{2 \pi}\left(\frac{\varepsilon_{\mathrm{m}}^{\prime}+\varepsilon_{\mathrm{s}}}{\varepsilon_{\mathrm{s}}^{2}}\right)^{1 / 2}
$$


where $\lambda$ was the wavelength of light in vacuum, and $\varepsilon^{\prime}{ }_{\mathrm{m}}$ was the real part of $\varepsilon_{\mathrm{m}}$. For a dielectric value of a refractive index ranging from 1.33 (water) to 1.38 (bovine serum albumin), ${ }^{33}$ $z$ could be estimated as $\sim 215.8-233.3 \mathrm{~nm}$, indicating the capability of detecting multilayers of bio/chemical molecules, including peptides and proteins on the metal.

\section{Results}

Figure 2 schematically illustrates the procedures for Fbg sensing, which cover from the sensor surface treatment to the surface regeneration. Firstly, the metal surface in the flow cell was cleaned by flowing PBST. Then, HP $(1 \mu \mathrm{g} / \mathrm{mL})$ was injected for immobilization on the Ni surface (1). The coordinate metal bonding of IM with Ni through nitrogen electrons enabled HP to be immobilized. We used Fbg antibody for stable bonding of Fbg with the surface, even in the presence of surface washout using PBST buffer. This IgG can also be used for selective bonding with Fbg in cases where various other kinds of proteins are present together, which was not our case. We injected Fbg antibody, IgG $(0.375 \mu \mathrm{g} / \mathrm{mL}$ concentration, enzyme-linked immunosorbent assay dilution procedure 4,000 times) into the flow cell for IgG immobilization on HPs through peptide-peptide interaction (2). To prevent the nonspecific binding of Fbg molecules to sites other than $\operatorname{IgG}$, the sensor surface was passivated by
$\mathrm{B}(0.4 \%$, volume-to-volume ratio) (3) before immobilization of Fbg on the $\operatorname{IgG}$ (4). Note that injection of each layer of $\mathrm{HP}, \mathrm{IgG}, \mathrm{B}$, and Fbg was followed by respective incubation of 30-minute duration. Again, a PBST solution was injected to wash away weakly bound molecules after each incubation. For the regeneration of the Ni surface, IM (20 mM) was injected to eliminate HP (5), and the final regeneration of the Ni surface (7) was performed with $1 \mathrm{M} \mathrm{ACT} \mathrm{and}$ PBST (6).

The Ni surface regeneration could be checked by comparing the output power level of the fiber sensor between before (1) and after (6). In addition, the whole procedures (1)-(6) were repeated using the so-called regenerated Ni surface, to confirm the same (or similar) pattern of the sensor output signal in the repeats of identical procedures.

\section{Discussion}

Figure 3A shows the measured fiber output power in a real time, as a series of liquids of PBST, HP, IgG, B, four different concentrations of Fbg, IM, ACT, and PBST were injected successively. Injection of the series of liquids was followed by another set of injections of the same series of liquids as mentioned earlier. In both series of injected liquids, four different Fbg concentrations, that is, $10 \mathrm{ng} / \mathrm{mL}, 100 \mathrm{ng} / \mathrm{mL}$, $500 \mathrm{ng} / \mathrm{mL}$, and $1,000 \mathrm{ng} / \mathrm{mL}$, were used. Each circular point

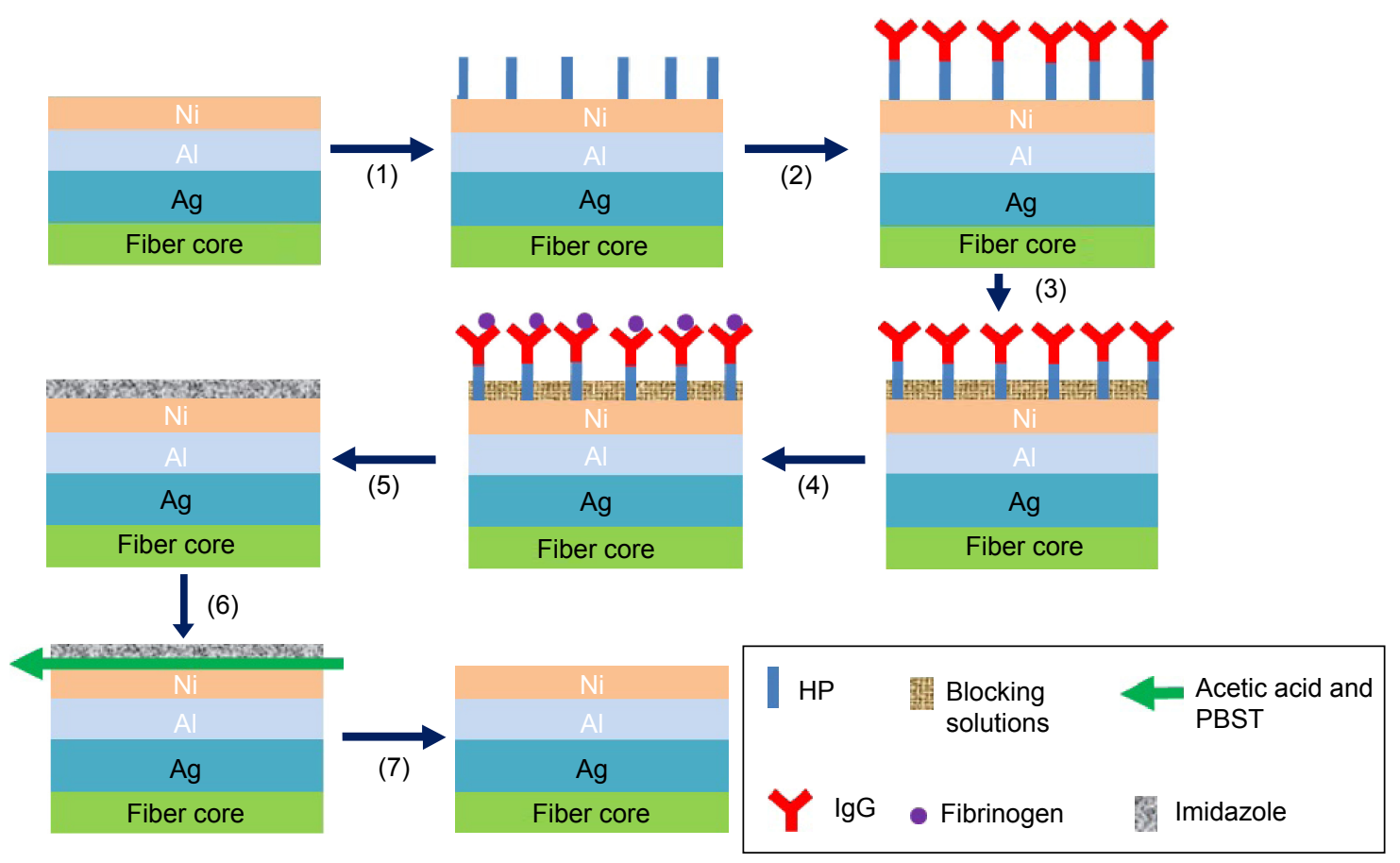

Figure 2 Procedures for regenerative sensing.

Notes: (I): HP immobilization; (2): association of IgG with HP; (3): passivation of surface with a blocking solution; (4): Fbg adsorption to IgG; (5): removing HP by imidazole; (6): removing imidazole by acetic acid and PBST; and (7): regenerated metal surface.

Abbreviations: HP, histidine-tagged peptide; IgG, immunoglobulin G (fibrinogen antibody); Fbg, fibrinogen; PBST, phosphate-buffered saline with Tween 20. 

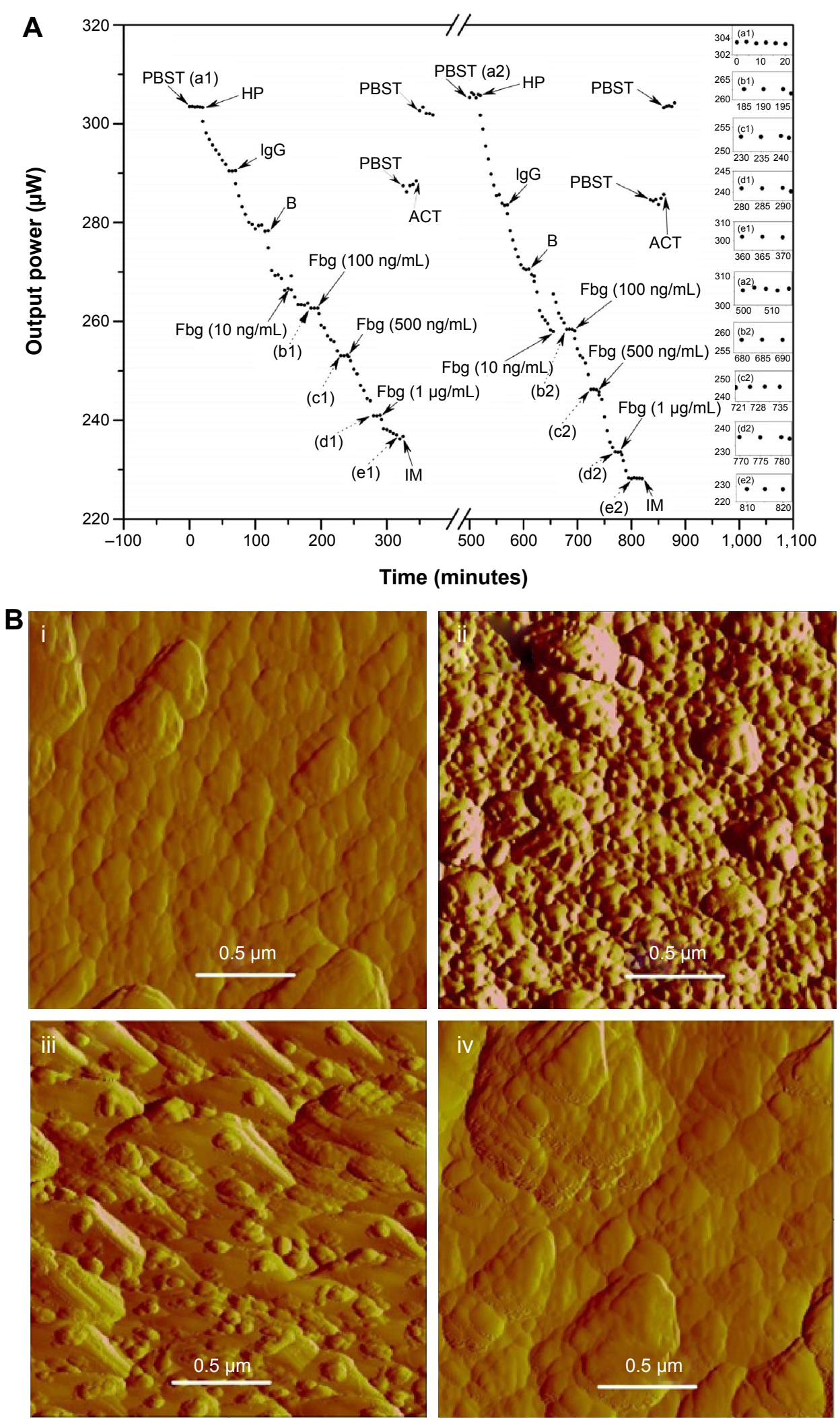

Figure 3 The sensor signals and the sensing surface regeneration.

Notes: (A) The SPR fiber sensor signals with a series of biochemical liquids injected for real-time label-free Fbg detection. Regeneration of metal ( $\mathrm{Ni}$ ) surface was achieved double times with the same fiber sensor. (B) AFM image for checking the metal (Ni) surface regeneration: (i) initial state, (ii) after immobilization of I $\mu g / \mathrm{mL}$ fibrinogen, (iii) after washing with imidazole, and (iv) after washing with ACT and PBST.

Abbreviations: PBST, phosphate-buffered saline with Tween 20; HP, histidine-tagged peptide ( $\mu \mathrm{g} / \mathrm{mL}$ ); $\operatorname{lgG}$, immunoglobulin $\mathrm{G}$ (fibrinogen antibody, $0.375 \mu \mathrm{g} / \mathrm{mL}$ ); B, blocking buffer solution; Fbg, fibrinogen; IM, imidazole (20 mM); ACT, acetic acid; SPR, surface plasmon resonance; AFM, atomic force microscopy. 
Table I Incubation time for HP, IgG, and Fbg

\begin{tabular}{|c|c|c|c|c|c|c|}
\hline & \multirow[t]{2}{*}{ HP } & \multirow[t]{2}{*}{ IgG } & \multicolumn{4}{|l|}{ Fbg } \\
\hline & & & 10 ng/mL & 100 ng/mL & 500 ng/mL & $1,000 \mathrm{ng} / \mathrm{mL}$ \\
\hline First series & 40 minutes & 30 minutes & 35 minutes & 35 minutes & 40 minutes & 25 minutes \\
\hline Second series & 40 minutes & 30 minutes & 30 minutes & 35 minutes & 35 minutes & 30 minutes \\
\hline
\end{tabular}

Abbreviations: HP, histidine-tagged peptide; IgG, immunoglobulin G; Fbg, fibrinogen.

in Figure 3A represents the averaged value of sensor output power over 1 minute.

Note that Fbg of lower concentration was injected before injection of higher concentration, to clarify the signal change due to the lower concentration. The subsequent injection of higher concentration could lead to additional signal change. This led us to estimate that, for example, the total signal change induced by injection of $500 \mathrm{ng} / \mathrm{mL}$ Fbg should be the sum of those induced by $10 \mathrm{ng} / \mathrm{mL}, 100 \mathrm{ng} / \mathrm{mL}$, and $500 \mathrm{ng} / \mathrm{mL}$ owing to the series of injection.

It was visible that injection of each liquid tended to cause rapid decreases in the sensor output, and the following incubation saturated the output to the stabilized one. The insets of Figure 3A display the stabilized sensor output (over $\sim 15$ minutes) for each Fbg concentration. The incubation time for a certain liquid immobilization could be defined as the time interval between the liquid injection and the start of the stabilized signal. The incubation time for HP, IgG, and Fbg from the measurement was estimated, as shown in Table 1.

As expected, larger changes in the sensor output power were observed from higher Fbg concentrations. Note that successive injections of IM, ACT, and PBST recovered the sensor output level nearly to that of the sensor output at initial state. Thus, the successive second regeneration of the sensor metal surface of the same fiber was demonstrated. This indicated that the layers of HP, IgG, and Fbg were physically removed successfully, since the fiber sensor was sensitive only to refractive indices of media on the sensor metal surface. Figure 3B shows atomic force microscopy images displaying physical regeneration of the Ni surface on the fiber sensor head, using IM, ACT, and PBST. It was also worth noting that the similar behavior of the observed sensor responses in the second series of liquid injection in comparison to the first series implied that the regenerated metal surface of the fiber sensor could support for a chemically reusable sensing platform, as well as physically reusable one.

The standard deviation of the sensor output power was measured (over 10 minutes time span) at the time just before the first Fbg was injected for each series of liquid injection. This meant that the standard deviation was obtained when PBST,
HP, IgG, and B were present on the sensor metal surface. This standard deviation represented the sensor noise level $(\Delta)$, which was used to estimate its detection $\operatorname{limit}^{34}\left(S_{\text {lim }}\right)$.

$$
S_{\text {lim }}=(3 \Delta)(\partial C / \partial P)
$$

where $C$ was the concentration of $\mathrm{Fbg}$, and $P$ was the sensor output power level. The $S_{\lim }$ for the first-series injection was estimated to be approximately $3.40 \mathrm{ng} / \mathrm{mL}$, corresponding to Fbg concentration of $\sim 10 \mathrm{pM}$. $S_{\lim }$ for the second-series injection was $11.21 \mathrm{ng} / \mathrm{mL}(32.97 \mathrm{pM})$. This difference was associated with the incomplete regeneration of the sensor metal surface as shown in Table 2. We believe that the imperfection of regeneration resulted from incomplete removal of HP and remaining plasma proteins adsorbed nonspecifically on it. In addition, there is a possibility that the used acid may change the metal surface state. This may have reduced its detection limit in the second series of liquid injection. The sensor platform presented allowed the detection limits which were comparable to a conventional enzyme-linked immunosorbent assay method ${ }^{35}$ or a typical SPR sensor system based on the prism-coupled Kretschman-Raether configuration. The estimated detection limits were believed to be lower than that required for diagnosis of the aforementioned diseases. Moreover, these detection limits for specific detection of Fbg were lower than that using Raman spectroscopy ${ }^{36}$ or comparable to those reported using local SPR excited by nanoparticles. ${ }^{37,38}$

Figure 4 shows the differential changes in the sensor output power as a function of Fbg concentration by averaging measured data obtained with all Fbg concentrations of both series of liquid injections. Note that nonzero four concentrations of $10 \mathrm{ng} / \mathrm{mL}, 100 \mathrm{ng} / \mathrm{mL}, 500 \mathrm{ng} / \mathrm{mL}$, and $1,000 \mathrm{ng} / \mathrm{mL}$ were used in a row. This means that the

Table 2 Regeneration degree of the sensor surface for both series of liquid injection

\begin{tabular}{lll}
\hline & $\begin{array}{l}\text { After } \\
\text { IM washing }\end{array}$ & $\begin{array}{l}\text { After washing } \\
\text { with ACT and PBST }\end{array}$ \\
\hline First series & $76.83 \%$ & $97.85 \%$ \\
Second series & $72.82 \%$ & $97.05 \%$ \\
\hline
\end{tabular}

Abbreviations: IM, imidazole; ACT, acetic acid; PBST, phosphate-buffered saline with Tween 20. 


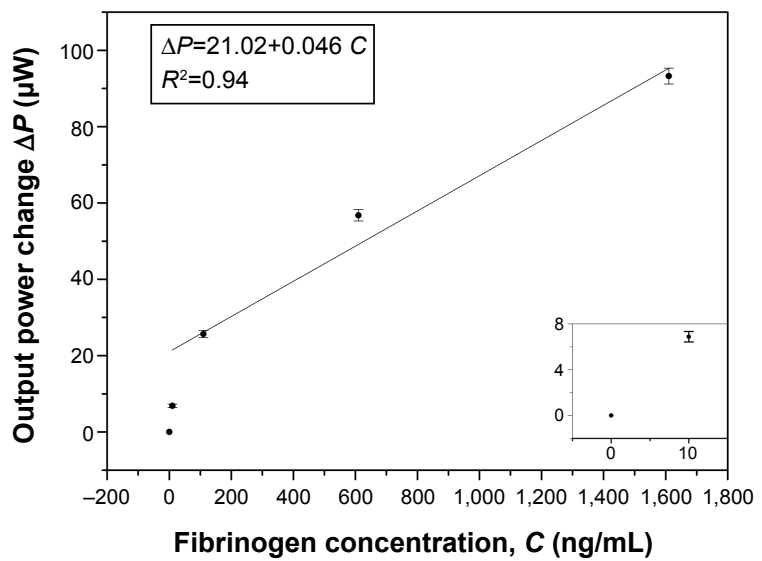

Figure 4 Differential change in the sensor output power with increasing concentration of fibrinogen.

Notes: $\Delta P$ denotes the change in sensor output power, and $C$ is the Fbg concentration accumulated on the sensor surface in a series injection of different Fbg concentrations.

ultimate concentrations that caused signal to change from that immediately before the first concentration injection must be reestimated as accumulated ones, that is, $10 \mathrm{ng} / \mathrm{mL}$, $110 \mathrm{ng} / \mathrm{mL}, 610 \mathrm{ng} / \mathrm{mL}$, and 1,610 ng/mL. In this regard, the concentration range of Fbg detected was $\sim 1,610 \mathrm{ng} / \mathrm{mL}$. Note that the concentration range of Fbg relied not only on detection device characteristics but also on the concentration of Fbg antibody ( $\mathrm{IgG}$ ) immobilized on the sensing surface. It is generally seen that the more the concentration of IgG immobilized is, the wider the concentration range of $\mathrm{Fbg}$ detected is.

Higher concentrations produced larger changes in the output power in an approximately linear fashion. However, the plot showed nonlinear behavior at around the lowest concentration (10 $\mathrm{ng} / \mathrm{mL})$, accounting for the steeper slope of the sensor signal change with respect to the Fbg concentration change. This is due to the fact that higher intensity of SPR wave was present at region closer to the metal surface. This led to stronger coupling between SPR wave and the Fbg molecules.

The use of HP for antibody immobilization onto Ni surface could offer several benefits to the sensing surface treatment for a label-free optical immunoassay, as described in the following. First, the use of HP could allow simultaneous removal of a pair of a target protein and its antibody, leading to the regeneration of the sensor metal surface. As described earlier, IM with ACT and buffer solution (PBST in this work) could efficiently eliminate HP, the antibody $\mathrm{IgG}$, and Fbg (target protein) in recovering Ni surface for sensor reusability. As shown in Figure 5, nitrogen $(\mathrm{N})$, the electron donor of the IM ring of histidine molecules, formed the coordinate metal bonds with $\mathrm{Ni}$. A carboxyl acid group of the peptide side of HP was responsible for its bonding with an antibody IgG. For the regeneration of Ni surface, we injected IM (20 mM with 10-minute incubation) to break $\mathrm{HP}$ bonds with Ni. This enabled subsequent elimination of IM molecules away from the Ni surface, and therefore, a pair of IgG and Fbg would be washed away from the sensor surface by flowing ACT and PBST. Secondly, HP could be used to immobilize different kinds of antibodies through engineering of its constituent peptides, thus supporting its applicability to various proteins sensing in a label-free biosensor. Lastly, the use of HP could enable one to avoid

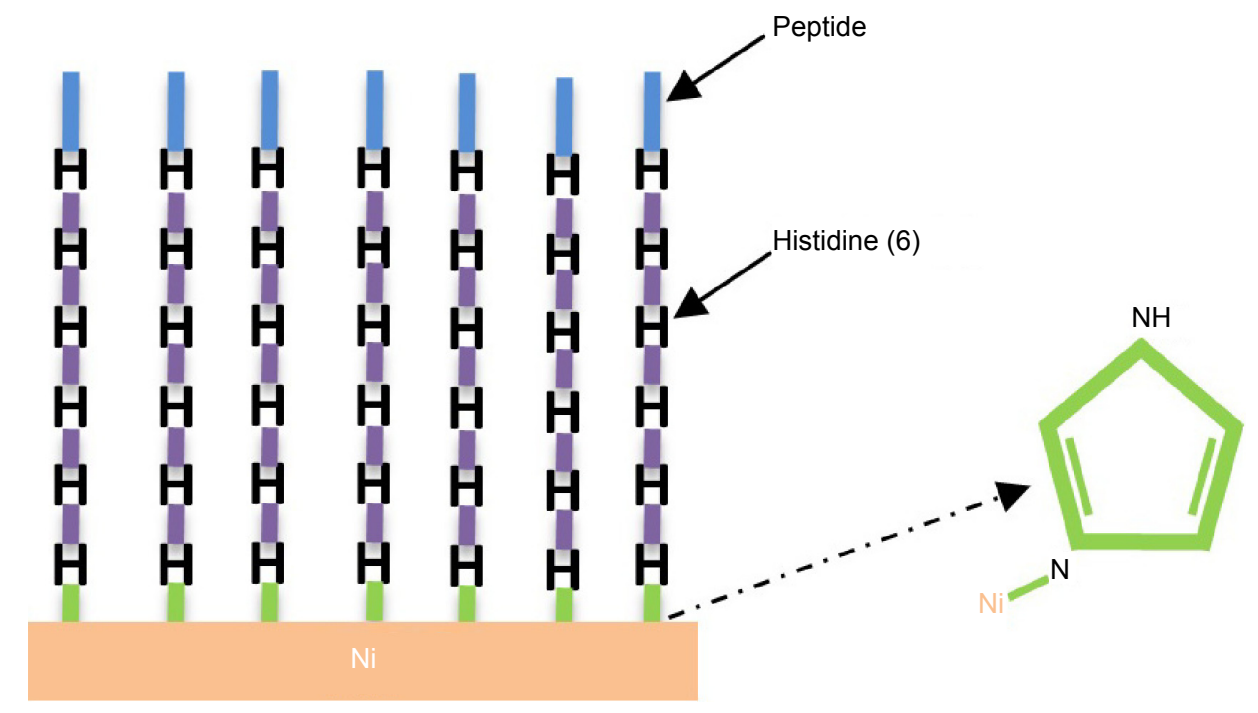

Figure $\mathbf{5}$ Immobilization of HP on the Ni surface. Abbreviation: HP, histidine-tagged peptide. 
denaturalization of a sensor metal surface, which may be encountered when whole metal surface was treated with toxic chemical cross-linker. ${ }^{39,40}$

Table 2 illustrates the degrees of regeneration of the metal surface, which represents how close was the signal (sensor output power) recovered from binding of the last Fbg concentrations toward the original (start) signal (before HP injection), as a result of injection of IM, ACT, and PBST. In the first series of liquid injection, $\sim 77 \%$ signal recovery was achieved by IM injection, and eventually $\sim 98 \%$ recovery by additional washing with ACT and PBST. Similarly, in the second series of liquid injection, IM injection produced $73 \%$ signal recovery with subsequent signal recovery of $97 \%$ by additional ACT and PBST. This meant that the regeneration of Ni surface could be fulfilled multiple times for the sensor reusability. The procedures required for the metal surface regeneration turned out to be relatively simple compared to those using toxic chemical treatment which could damage and denature the sensor metal surface, such as piranha solution ${ }^{41}$ and sodium hypochlorite solution methods. ${ }^{42}$

\section{Conclusion}

A label-free regenerative immuno-biosensor was demonstrated with a sensor key head, which comprised a multimode optical fiber with SPR coating for detecting Fbg of various concentrations quantitatively in a real-time manner. The key ingredient for regeneration procedure of immuno-assay was the immobilized HP layer on the sensor metal surface. This HP layer for binding IgG was able to be eliminated from the metal surface by using IM, ACT, and PBST for such regeneration.

The regeneration was demonstrated twice (using two identical series of liquid injection), to check its chemical validity, as well as the physical one. The regeneration of the sensor metal surface could open potential applications for biosensors in needs for limited human access, such as cosmic space, underground, and deserted lands. The detection limit of the sensor was estimated to be $\sim 3.40 \mathrm{ng} / \mathrm{mL}(10 \mathrm{pM})$ and $11.21 \mathrm{ng} / \mathrm{mL}$ (32.97 pM) in the first and second series of liquid injection, respectively. The label-free detection platform presented may find potential applications for Fbg-based diagnosis of cardiovascular disease, strokes, heart disease, and Alzheimer's disease.

Actual application of this sensor device in the practical use would require calibration of the sensor signal in diagnosing different concentrations of injected Fbg. However, one must note that this calibration would depend on IgG concentrations and metal coating thickness, which would determine the SPR wave decaying depth normal to the metal surface.
The presented sensing scheme in using a multimode optical fiber used neither any spectroscopic technique nor measurement of incident angle of an optical beam, unlike conventional SPR biosensor, but the present sensor would be miniaturized easily and integrated into a lab-on-chip platform.

\section{Acknowledgments}

This research was supported by Basic Science Research Program through the National Research Foundation of Korea (NRF) funded by the Ministry of Education, Science and Technology (2011-0009353) and also by the Industrial Core Technology Development Program (grant number 10049051, Development of bench-top automatic immunoassay system with intelligent quality control features for screening cancer or chronic diseases in local clinical setting) funded by the Ministry of Trade, Industry and Energy (MI, South Korea).

\section{Disclosure}

The authors report no conflicts of interest in this work.

\section{References}

1. Liedberg B, Nylander C, Lundström I. Biosensing with surface plasmon resonance - how it all started. Biosens Bioelectron. 1995; 10:i-xi.

2. Morton TA, Myszka DG, Chaiken IM. Interpreting complex binding kinetics from optical biosensors: a comparison of analysis by linearization, the integrated rate equation, and numerical integration. Anal Biochem. 1995;227:176-185.

3. Green RJ, Frazier RA, ShakesheffKM, Davies MC, Roberts CJ, Tendler SJ. Surface plasmon resonance analysis of dynamic biological interactions with biomaterials. Biomaterials. 2000;21:1823-1835.

4. Song X, Nolan J, Swanson BI. Optical biosensor based on fluorescence resonance energy transfer: ultrasensitive and specific detection of protein toxins. J Am Chem Soc. 1998;120:11514-11515.

5. Chen I, Ting AY. Site-specific labeling of proteins with small molecules in live cells. Curr Opin Biotechnol. 2005;16:34-40.

6. Li IT, Pham E, Truong K. Protein biosensors based on the principle of fluorescence resonance energy transfer for monitoring cellular dynamics. Biotechnol Lett. 2006;28:1971-1982.

7. Nath N, Chilkoti A. A colorimetric gold nanoparticle biosensor: effect of particle size on sensitivity. In: Proceedings of the Second Joint. Texas: IEEE; 2002:574-575.

8. Taitt CR, Anderson GP, Ligler FS. Evanescent wave fluorescence biosensors. Biosens Bioelectron. 2005;20:2470-2487.

9. Edwards PR, Gill A, Pollard-Knight DV, et al. Kinetics of protein-protein interactions at the surface of an optical biosensor. Anal Biochem. 1995;231: 210-217.

10. Homola J, Yee SS, Gauglitz G. Surface plasmon resonance sensors: review. Sens Actuators B Chem. 1999;54:3-15.

11. Heas AJ, Chang L, Klein WL, Van Duyne RP. Detection of a biomarker for Alzheimer's disease from synthetic and clinical samples using a nanoscale optical biosensor. J Am Chem Soc. 2005;127: 2264-2271.

12. Guerreiro JRL, Frederiksen M, Bochenkov VE, De Freitas V, Ferreira Sales MG, Sutherland DS. Multifunctional biosensor based on localized surface plasmon resonance for monitoring small molecule-protein interaction. ACS Nano. 2014;8:7958-7967.

13. Oczkowski T, Zwierkowska E, Bartkowiak S. Application of cell-based biosensors for the detection of bacterial elicitor flagellin. Bioelectrochemistry. 2007;70:192-197. 
14. Rong G, Najmaie A, Sipe JE, Weiss SM. Nanoscale porous silicon waveguide for label-free DNA sensing. Biosens Bioelectron. 2008;23: 1572-1576.

15. Song SY, Choi HG, Hong JW, Kim BW, Sim SJ, Yoon HC. Selective antigen-antibody recognition on SPR sensor based on the heat-sensitive conformational change of poly (N-isopropylacrylamide). Colloids Surf A Physicochem Eng Asp. 2008;313:504-508.

16. Hoa XD, Kirk AG, Tabrizian M. Enhanced SPR response from patterned immobilization of surface bioreceptors on nano-gratings. Biosens Bioelectron. 2009;24:3043-3048.

17. Wijaya E, Lenaerts C, Maricot S, et al. Surface plasmon resonance-based biosensors: from the development of different SPR structures to novel surface functionalization strategies. Curr Opin Solid State Mater Sci. 2011;15:208-224.

18. Wu SY, Ho HP, Law WC, Lin C, Kong SK. Highly sensitive differential phase-sensitive surface plasmon resonance biosensor based on the Mach-Zehnder configuration. Opt Lett. 2004;29:2378-2380.

19. Chiu MH, Shih $\mathrm{CH}$, Chi MH. Optimum sensitivity of single-mode D-type optical fiber sensor in the intensity measurement. Sens Actuators B Chem. 2007;123:1120-1124.

20. Jang HS, Park KN, Kang CD, Kim JP, Sim SJ, Lee KS. Optical fiber SPR biosensor with sandwich assay for the detection of prostate specific antigen. Opt Commun. 2009;282:2827-2830.

21. Yanase Y, Araki A, Suzuki H, et al. Development of an optical fiber SPR sensor for living cell activation. Biosens Bioelectron. 2010;25: 1244-1247.

22. Nguyen TT, Lee EC, Ju H. Bimetal coated optical fiber sensors based on surface plasmon resonance induced change in birefringence and intensity. Opt Express. 2014;22:5590-5598.

23. Zoroddu MA, Medici S, Peana M. Copper and nickel binding in multihistidinic peptide fragments. J Inorg Biochem. 2009;103:1214-1220.

24. Ridker PM, Stampfer MJ, Rifai N. Novel risk factors for systemic atherosclerosis: a comparison of C-reactive protein, fibrinogen, homocysteine, lipoprotein (a), and standard cholesterol screening as predictors of peripheral arterial disease. JAMA. 2001;285:2481-2485.

25. Papageorgiou N, Tousoulis D, Miliou A, et al. Combined effects of fibrinogen genetic variability on atherosclerosis in patients with or without stable angina pectoris: focus on the coagulation cascade and endothelial function. Int J Cardiol. 2013;168:4602-4607.

26. Guo F, Liu J, Wang C, Liu N, Lu P. Fibrinogen, fibrin, and FDP induce $\mathrm{C}$-reactive protein generation in rat vascular smooth muscle cells: proinflammatory effect on atherosclerosis. Biochem Biophys Res Commun. 2009;390:942-946.

27. Okwuosa TM, Klein O, Chan C, et al. 13-Year long-term associations between changes in traditional cardiovascular risk factors and changes in fibrinogen levels: the coronary artery risk development in young adults (CARDIA) study. Atherosclerosis. 2013;226:214-219.
28. Cortes-Canteli M, Zamolodchikov D, Ahn HJ, Strickland S, Norris EH. Fibrinogen and altered hemoststis in Alzheimer's disease. J Alzheimers Dis. 2012;32:599-608.

29. Ma J, Xu A, Jia C, et al. Associations of fibrinogen with metabolic syndrome in rural Chinese population. J Atheroscler Thromb. 2010;17: 486-492.

30. Turaj W, Słowik A, Dziedzic T, et al. Increased plasma fibrinogen predicts one-year mortality in patients with acute ischemic stroke. J Neurol Sci. 2006;246:13-19.

31. Miesbach W, Schenk J, Alesci S, Lindhoff-Last E. Comparison of the fibrinogen clauss assay and the fibrinogen PT derived method in patients with dysfibrinogenemia. Thromb Res. 2010;126:e428-e433.

32. Raether H. Surface Plasmons on Smooth and Rough Surfaces and on Gratings. Berlin: Springer; 1988.

33. Hand DB. The refractivity of protein solutions. J Biol Chem. 1935;108 703-707.

34. Homola J. Surface plasmon resonance sensors for detection of chemical and biological species. Chem Rev. 2008;108:462-493.

35. Fibrinogen Human ELISA Kit ab108842. Available from: http://www. abcam.com/fibrinogen-human-elisa-kit-ab108842.html

36. Poon KW, Lyng FM, Knief P, et al. Quantitative reagent-free detection of fibrinogen levels in human blood plasma using Raman spectroscopy. Analyst. 2012;137:1807-1814.

37. Endo T, Yamamura S, Nagatani N, Morita Y, Takamura Y, Tamiya E. Localized surface plasmon resonance based optical biosensor using surface modified nanoparticle layer for label-free monitoring of antigenantibody reaction. Sci Technol Adv Mater. 2005;6:491-500.

38. Endo T, Kerman K, Nagatani N, et al. Multiple label-free detection of antigen-antibody reaction using localized surface plasmon resonance-based core-shell structured nanoparticle layer nanochip. Anal Chem. 2006;78: 6465-6475.

39. Lee JW, Sim SJ, Cho SM, Lee J. Characterization of a self-assembled monolayer of thiol on a gold surface and the fabrication of a biosensor chip based on surface plasmon resonance for detecting anti-GAD antibody. Biosens Bioelectron. 2005;20:1422-1427.

40. Kang CD, Lee SW, Park TH, Sim SJ. Performance enhancement of real-time detection of protozoan parasite, Cryptosporidium oocyst by a modified surface plasmon resonance (SPR) biosensor. Enzyme Microb Technol. 2006;39:387-390.

41. Vashist SK. A method for regenerating gold surface for prolonged reuse of gold-coated surface plasmon resonance chip. Anal Biochem. 2012;423: 23-25.

42. Wang R, Lajevardi-Khosh A, Choi S, Chae J. Regenerative surface plasmon resonance (SPR) biosensor: real-time measurement of fibrinogen in undiluted human serum using the competitive adsorption of proteins. Biosens Bioelectron. 2011;28:304-307.
International Journal of Nanomedicine

\section{Publish your work in this journal}

The International Journal of Nanomedicine is an international, peerreviewed journal focusing on the application of nanotechnology in diagnostics, therapeutics, and drug delivery systems throughout the biomedical field. This journal is indexed on PubMed Central, MedLine, CAS, SciSearch $®$, Current Contents $\AA /$ Clinical Medicine,

\section{Dovepress}

Journal Citation Reports/Science Edition, EMBase, Scopus and the Elsevier Bibliographic databases. The manuscript management system is completely online and includes a very quick and fair peer-review system, which is all easy to use. Visit http://www.dovepress.com/ testimonials.php to read real quotes from published authors. 